\title{
EFFECTS OF GS-441524 ON CLINICAL AND HEMATOCHEMICAL PARAMETERS OF CATS WITH EFFUSIVE FIP OVER 60 DAYS FOLLOW-UP
}

\author{
ERDEM GÜLERSOY ${ }^{1}$ AND MEHMET MADEN ${ }^{2}$ \\ ${ }^{1}$ Harran University, Faculty of Veterinary Medicine, Department of Internal Medicine, \\ Şanlıurfa, Turkey, ORCID: 0000-0001-8511-0150 \\ ${ }^{2}$ Selçuk University, Faculty of Veterinary Medicine, Department of Internal Medicine, \\ Konya, Turkey, ORCID: 0000-0003-2954-6763, Phone: +905333344042
}

Received: 25 July 2021; Accepted: 11 October 2021

\begin{abstract}
Feline infectious peritonitis (FIP) is an important disease characterized by granulomatous changes in various organs including the ocular and central nervous system. FIP infection is referred as the best candidate for antiviral drug development studies due to the ineffectiveness of vaccines and being a cause of high mortality. The most important antiviral drugs developed against RNA viruses are nucleoside analogues such as GS-441524. In this study, GS-441524 was used in the treatment of three naturally infected cats with ocular lesions diagnosed with effusive FIP. The treatment of cats was planned as GS-441524 (5 mg / kg, SC, daily) administration for 12 weeks along with fluid therapy on the admission day. The treatment process included follow-ups with clinical and laboratory examinations on the admission $5^{\text {th }}$, $15^{\text {th }}, 30^{\text {th }}, 60^{\text {th }}, 90^{\text {th }}$ and $120^{\text {th }}$ days. On the $5^{\text {th }}$ day, clinical signs including ocular abnormalities and on the $30^{\text {th }}$ day, laboratory findings were significantly improved in all 3 cats. While the cats were expected for monthly follow-ups, it was learned that the cats died on the $58^{\text {th }}, 60^{\text {th }}$ and $62^{\text {nd }}$ days. It was concluded that GS-441524 (5 $\mathrm{mg} / \mathrm{kg} / \mathrm{day}, \mathrm{SC}$ ) has been proven to be beneficial for improving clinical, laboratory findings and animal welfare. However, it was evaluated that clinical studies involving more cases are required in order to determine the clinical efficacy of nucleoside analogues and investigate the causes of deaths occurred on the $58^{\text {th }}, 60^{\text {th }}$ and $62^{\text {nd }}$ days of the treatment period with no symptoms that would grab the attention of the owners.
\end{abstract}

Keywords: Coronavirus; feline infectious peritonitis; hematology; nucleoside analogues; treatment

Corresponding author: Erdem Gülersoy

E-mail address: egulersoy@ harran.edu.tr

Present address: Harran University, Faculty of Veterinary Medicine, Department of Internal Medicine, Şanliurfa, Turkey 


\section{INTRODUCTION}

Coronaviruses can be seen in many mammal species, including humans and birds, causing acute or chronic infections due to cell tropism (Enjuanes et al., 2006). Feline coronaviruses (FCoV) are pleomorphic, enveloped, single-stranded and non-segmented RNA viruses (Pedersen, 2009). There are 2 pathotypes of feline coronaviruses: feline enteric coronavirus (FECV), which is the enteric biotype and feline infectious peritonitis virus (FIPV), which is the virulent biotype (Kipar and Meli, 2014). Feline infectious peritonitis (FIP) is generally seen in cats younger than 2-3 years and older than 10 years. Although the morbidity rate is low $(10 \%)$, the mortality rate is quite high $(90 \%)$. The course of the disease varies depending on the immune status of the host (Hartmann, 2005). FIP has 3 major clinical forms: effusive (exudative), dry (non-effusive, non-exudative, granulomatous, parenchymatous) and mixed. Nonspecific symptoms such as anorexia, weight loss, depression and fever develop in FIP infection (Kipar and Meli, 2014). The clinical appearance may vary according to the involvement of kidney, liver, eye, pancreas and central nervous system (CNS). Clinical and pathological laboratory findings are related to vasculitis and related organ failure. The effusive form is characterized by fibrinous peritonitis, pleuritis or pericarditis with effusion in the abdomen, thorax and/or pericardium. The non-effusive form is characterized by granulomatous changes in the organs (Hartmann, 2005; Pedersen, 2009; Kipar and Meli, 2014).

Treatment of RNA and DNA virus infections in humans has focused on drugs that inhibit virus replication (De Clercq and Li, 2016). FIP infection is referred as the best candidate for antiviral drug development studies due to the ineffectiveness of vaccines, difficulty of protection and being cause of high rate of mortality (Dickinson, 2020). The most important antiviral drugs developed against RNA viruses are GS-5734 (Remdesivir, Gilead Sciences $®$ ) and GS441524 (Gilead Sciences Inc. ${ }^{\circledR}$, Foster City, California), which have been used against FIP infection in cats (Pedersen et al., 2019). In a study conducted on 31 cats naturally infected with FIP (Pedersen et al., 2019), the use of a nucleoside analogue GS-441524 at a dose of $5-10 \mathrm{mg} / \mathrm{kg}$ (SC, daily) it has been reported that regardless of the clinical form of the infection, it provides rapid clinical improvement in mentation, appetite and general activity in a period of 24-36 hours (Dickinson et al., 2020).

Although GS-441524 was reported to provide clinical improvement, to the best of the authors' knowledge, no study has been found that focused on the hematological and biochemical changes in cats with effusive FIP. Therefore, in this study, clinical and laboratory examination outcomes of GS-441524 (5 $\mathrm{mg} / \mathrm{kg}$, SC, daily) treatment over a period of approximately 2 months in 3 cats naturally infected with effusive FIP are evaluated.

\section{MATERIALS AND METHODS}

The animal material of the present study was 3 owned cats, which were admitted to Selcuk University Animal Hospital of Faculty of Veterinary Medicine for diagnosis and treatment purposes. Clinical examinations of all the cats were performed in the clinics of Department of 
Internal Medicine of the Animal Hospital and the laboratory analyzes of the samples of the cats were performed in the Central Laboratory of the Animal Hospital between February-April 2021. The diagnosis of effusive FIP was made on the basis of CBC, serum biochemistry analysis including albumin, globulin and total protein concentrations (Kipar and Meli, 2014) and albumin:globulin ratio (A:G <0.8) (Worthing et al., 2012) measurements, presence of clinical findings such as anorexia, lethargy, weight loss, jaundice, effusion, ocular lesions, upper respiratory signs and positive FCoV Ag test (Pedersen et al., 2019) along with imagining techniques (Figure 1). In order to rule out the diseases that may cause similar clinical findings to FIP, FIV Ab (Asan Easy Test ${ }^{\circledR}$ FIV Ab / FeLV Ag, ASANPharm, Korea), FeLV Ag (Asan Easy Test ${ }^{\circledR}$ FIV $\mathrm{Ab} / \mathrm{FeLV}$ Ag, ASANPharm, Korea) and FPV Ag (Asan Easy Test ${ }^{\circledR}$ FPV, ASANPharm, Korea) tests were performed. Also, diseases causing clinical symptoms similar to FIP infection such as lymphoma, cardiomyopathy, septic peritonitis, pyothorax, and chylothorax (Barlough, 1984; Addie and Jarrett 1998; Andrew, 2000) were considered in the differential diagnosis list. Permission was obtained from the owners of the three cats included in the study to use the images and data of the cats.

\section{Animals}

Cat 1. Domestic, Bombay, one-year-old, $3.6 \mathrm{~kg}$, non-neutered male cat was brought with complaints of weakness, loss of appetite, stagnation and increasing abdominal distention.

Cat 2. Eleven-month-old, $3.4 \mathrm{~kg}$, nonneutered male Scottish cat was brought with complaints of weakness, loss of appetite and constant sleepiness.

Cat 3. Bombay, nine-month-old, $2.9 \mathrm{~kg}$, non-neutered male cat was brought with complaints of stagnation, loss of appetite and decreased defecation.

\section{Sample Collection}

Blood samples of all the cats, with minimal restraint in order to not cause stress, were taken by vena cephalica venepunction $(3-5 \mathrm{~mL})$ by the same personnel. Effusion samples of all the cats were taken under ultrasound guidance (Mindray DC-6, USA).

\section{Laboratory Analyzes}

To perform a complete blood count (CBC), an autoanalyzer (MS4e ${ }^{\circledR}$, Melet Schloesing Laboratoires, France) and to perform serum biochemistry, a chemistry analyzer (BT 3000® plus analyser, Biotecnica Instruments SpA, Rome, Italy) was used. All measurements were performed within the 15-30 minutes after sampling.

\section{Statistical Analysis}

SPSS 21.00 (IBM®, USA) software was used for the statistical analysis of the variation of hematological and biochemical parameters. KolmogorovSmirnov test was performed to determine whether the data were parametric or nonparametric. All parametric data were presented as mean \pm standard deviation (SD). The ANOVA procedure was used to compare all the data based on the follow-up intervals. Statistical significance was considered as $\mathrm{P}<0.05$. Statistical analysis results of timedependent hematological and biochemical parameters were presented in Table 1 and 2, respectively. 


\section{RESULTS}

\section{Clinical Findings}

Cat 1. During physical examination, abdominal ballotman, normothermia $\left(38.8{ }^{\circ} \mathrm{C}\right)$, tachycardia (220 beats/min), dyspnea, tachypnea (60 breaths/min) and icterus were determined. Abdominal effusion was confirmed by direct radiography and ultrasonography and it was determined to be exudate based on the physical and dipstick examinations (3+ leukocytes, 3+ total protein, 1.030 SpG) (Figure 1). Also, the Rivolta test was positive (Figure 2). Pigmented keratic precipitates and corneal edema were detected in ocular fundus examination (Figure 3 ).

Cat 2. Physical examination revealed hypothermia $\left(37.8{ }^{\circ} \mathrm{C}\right)$ and bradycardia (132 beats/min), abdominal ballotman as well as pain on kidney palpation. Abdominal effusion was confirmed to be exudate based on positive Rivolta rest, physical and dipstick examinations (2+ leukocytes, 3+ total protein, $1.040 \mathrm{SpG}$ ) results (Figure 1 and 2). Pigmented keratic precipitates, aqueous flare and corneal edema were detected in ocular fundus examination (Figure 3 ).

Cat 3. Physical examination revealed marked loss of skin turgor, hyperthermia $\left(39.4{ }^{\circ} \mathrm{C}\right)$, tachycardia (200 beats/min), tachypnea (64 breaths/min), prolonged capillary filling time ( $>4 \mathrm{sec})$ and pallor of mucous membranes. Similar to the results of the other cats, the effusion was exudate in character $(1+$ leukocytes, 3+ total protein, 1.035 $\mathrm{SpG}$ ) (Figure 1 and $2)$. Severe aqueous flare and corneal edema were detected in ocular fundus examination (Figure 3).

As a result of daily use of $5 \mathrm{mg} / \mathrm{kg} \mathrm{SC}$ of GS-441524 along with fluid treatment with crystalloids, significant improvement in clinical findings including ocular lesions in such a short period of 5 days were determined in the present report (Figure 3).

\section{Hematological Findings}

As a result of statistical analysis of hematological parameters based on the follow-up intervals, fluctuant courses were observed in $\mathrm{MCH}$ and $\mathrm{MCHC}$ levels $(\mathrm{p}<0.05)$. Hematological findings were presented in Table 1.

\section{Biochemical Findings}

As a result of statistical analysis of biochemical parameters based on the follow-up intervals, fluctuant courses were observed in amylase, magnesium, triglyceride and CPK levels $(\mathrm{p}<0.05)$. Biochemical findings were presented in Table 2.

While the treatment was continuing, it was learned from the owners that all the cats died (Cat 1 on $60^{\text {th }}$ day; Cat 2 on $58^{\text {th }}$ day; Cat 3 on $62^{\text {nd }}$ day) and the causes of death could not be investigated due to the owners' refusal of necropsy. 
Table 1. Hematological findings

\begin{tabular}{lccccc}
\hline Parameters* & $\mathbf{0}^{\text {th }}$ day & $\mathbf{5}^{\text {th }}$ day & $\mathbf{1 5}^{\text {th }}$ day & $\mathbf{3 0}^{\text {th }}$ day & P value \\
\hline WBC $\left(\times 10^{9} / \mathrm{L}\right)$ & $10.27 \pm 2.09$ & $10.48 \pm 5.29$ & $12.19 \pm 7.06$ & $10.80 \pm 2$ & 0.955 \\
\hline Lym $\left(\times 10^{9} / \mathrm{L}\right)$ & $3.79 \pm 0.47$ & $4.46 \pm 2.91$ & $3.85 \pm 1.59$ & $3.30 \pm 1.82$ & 0.902 \\
\hline Mon $\left(\times 10^{9} / \mathrm{L}\right)$ & $1.63 \pm 0.26$ & $1.47 \pm 0.75$ & $2.83 \pm 3.37$ & $0.63 \pm 0.41$ & 0.526 \\
\hline Gra $\left(\times 10^{9} / \mathrm{L}\right)$ & $4.84 \pm 2.16$ & $4.53 \pm 2.46$ & $5.51 \pm 2.66$ & $8.62 \pm 3.26$ & 0.292 \\
\hline RBC $\left(\times 10^{12} / \mathrm{L}\right)$ & $7.29 \pm 3.13$ & $9.38 \pm 3.57$ & $9.02 \pm 2.43$ & $7.96 \pm 1.44$ & 0.782 \\
\hline MCV $(\mathrm{fl})$ & $41.83 \pm 3.36$ & $46.23 \pm 9.28$ & $50.13 \pm 5.98$ & $59.23 \pm 12.58$ & 0.159 \\
\hline Het $(\mathrm{L} / \mathrm{L})$ & $30.43 \pm 13.49$ & $41.26 \pm 8.80$ & $44.60 \pm 9.39$ & $46.63 \pm 7.56$ & 0.277 \\
\hline MCH $(\mathrm{pg})$ & $13.83 \pm 1.09^{\text {ab }}$ & $9.30 \pm 0.78^{\mathrm{b}}$ & $14.10 \pm 1.99^{\mathrm{ab}}$ & $16.80 \pm 3.31^{\mathrm{a}}$ & 0.013 \\
\hline MCHC $(\mathrm{g} / \mathrm{dL})$ & $33.36 \pm 4.66^{\mathrm{a}}$ & $20.96 \pm 6.26^{\mathrm{b}}$ & $28.43 \pm 1.93^{\mathrm{ab}}$ & $28.70 \pm 4.68^{\mathrm{ab}}$ & 0.050 \\
\hline Hb $(\mathrm{g} / \mathrm{dL})$ & $8.70 \pm 3.16$ & $8.93 \pm 4$ & $12.10 \pm 2.52$ & $13.16 \pm 0.46$ & 0.214 \\
\hline RDW $(\%)$ & $11.93 \pm 2.40$ & $11.80 \pm 1.96$ & $10.63 \pm 0.35$ & $10.36 \pm 1.02$ & 0.576 \\
\hline
\end{tabular}

WBC: leukocyte, Lym: lymphocyte, Mon: monocyte, Gra: granulocyte, RBC: red blood cells, MCV: mean corpuscular volume, MCH: mean corpuscular haemoglobin, MCHC: mean corpuscular haemoglobin concentration, Hct: hemotocrit, Hb: haemoglobin, The letters ( $a, b$ and c) show the statistically significant differences between the follow-up days. $\$$ Units are based on Klaassen, 1999 and Moritz et al., 2004.

Table 2. Biochemical findings.

\begin{tabular}{|c|c|c|c|c|c|}
\hline Parameters* $*$ & $0^{\text {th }}$ day & $5^{\text {th }}$ day & $15^{\text {th }}$ day & $30^{\text {th }}$ day & $\begin{array}{c}\mathbf{P} \\
\text { value }\end{array}$ \\
\hline BUN (mmol/L) & $83.96 \pm 45.38$ & $49.63 \pm 48.80$ & $14.50 \pm 0.62$ & $11.36 \pm 4.54$ & 0.091 \\
\hline Creatinine $(\mathrm{mmol} / \mathrm{L})$ & $7.56 \pm 6.71$ & $3.63 \pm 3.23$ & $1 \pm 0.30$ & $1.13 \pm 0.50$ & 0.189 \\
\hline AST (U/L) & $66.73 \pm 58$ & $84.87 \pm 67$ & $19.33 \pm 3.21$ & $22.33 \pm 7.02$ & 0.628 \\
\hline $\mathbf{A L P}(\mathrm{U} / \mathrm{L})$ & $31.33 \pm 22.03$ & $643.26 \pm 405.33$ & $216.81 \pm 160$ & $41.66 \pm 23.75$ & 0.535 \\
\hline ALT (U/L) & $34 \pm 10.14$ & $295.91 \pm 207.33$ & $60 \pm 47.28$ & $22.33 \pm 3.51$ & 0.449 \\
\hline Amylase (U/L) & $2174.33 \pm 687.82^{\mathrm{a}}$ & $1940.33 \pm 207.05^{\mathrm{ab}}$ & $733.33 \pm 381.58^{\mathrm{c}}$ & $918.66 \pm 297.04^{\mathrm{bc}}$ & 0.008 \\
\hline Glucose $(\mathrm{mmol} / \mathrm{L})$ & $146.33 \pm 48.26$ & $106.66 \pm 23.11$ & $105.66 \pm 6.42$ & $95 \pm 14.10$ & 0.197 \\
\hline $\mathbf{L D H}(\mathrm{U} / \mathrm{L})$ & $433.66 \pm 324.09$ & $153 \pm 52.45$ & $110.66 \pm 75.95$ & $252.66 \pm 211.59$ & 0.272 \\
\hline Total bil. (umol/L) & $0.83 \pm 0.55$ & $1.10 \pm 0.78$ & $0.6 \pm 0.6$ & $0.33 \pm 0.32$ & 0.471 \\
\hline Calcium $(\mathrm{mmol} / \mathrm{L})$ & $9.40 \pm 3.10$ & $9.13 \pm 1.51$ & $9.33 \pm 1.85$ & $8.50 \pm 2.40$ & 0.960 \\
\hline Direct bil. (umol/L) & $0.43 \pm 0.15$ & $0.43 \pm 0.35$ & $0.13 \pm 0.05$ & $0.16 \pm 0.11$ & 0.196 \\
\hline Phosphorous (mmol/L) & $11.63 \pm 4.36$ & $9.26 \pm 5.23$ & $3.83 \pm 0.15$ & $5.80 \pm 2.17$ & 0.105 \\
\hline Cholesterol $(\mathrm{mmol} / \mathrm{L})$ & $282.33 \pm 201.79$ & $221.33 \pm 127.41$ & $198.33 \pm 74.09$ & $153 \pm 25.23$ & 0.662 \\
\hline Magnesium (mmol/L) & $3.43 \pm 0.90^{\mathrm{a}}$ & $2.63 \pm 0.90^{\mathrm{ab}}$ & $1.46 \pm 0.47^{\mathrm{b}}$ & $1.60 \pm 0.17^{\mathrm{b}}$ & 0.025 \\
\hline Triglycerides $(\mathrm{mmol} / \mathrm{L})$ & $144.66 \pm 73.24^{\mathrm{a}}$ & $92.66 \pm 32.12^{\mathrm{ab}}$ & $44 \pm 2^{\mathrm{ab}}$ & $37 \pm 17.77^{\mathrm{b}}$ & 0.040 \\
\hline GGT $(\mathrm{U} / \mathrm{L})$ & $34.07 \pm 22.66$ & $19.07 \pm 14$ & $4.66 \pm 0.57$ & $4.66 \pm 2.88$ & 0.642 \\
\hline CPK (U/L) & $337 \pm 146.11^{\mathrm{a}}$ & $203.33 \pm 81.24^{\mathrm{ab}}$ & $61 \pm 3.60^{\mathrm{b}}$ & $145.66 \pm 76.42^{\mathrm{ab}}$ & 0.034 \\
\hline Total protein $(\mathrm{g} / \mathrm{L})$ & $7.73 \pm 0.55$ & $7.63 \pm 1.20$ & $6.80 \pm 0.26$ & $7.20 \pm 2.02$ & 0.775 \\
\hline Albumin (g/L) & $3 \pm 0.20$ & $2.73 \pm 0.83$ & $2.93 \pm 0.49$ & $2.66 \pm 0.5$ & 0.821 \\
\hline Globulin (g/L) & $4.73 \pm 0.35$ & $4.90 \pm 1.49$ & $3.86 \pm 0.50$ & $4.53 \pm 2.07$ & 0.787 \\
\hline$A: G \dagger$ & $0.6 \pm 0$ & $0.60 \pm 0.36$ & $0.76 \pm 0.20$ & $0.66 \pm 0.25$ & 0.815 \\
\hline
\end{tabular}

BUN: Blood urea nitrogen, AST: aspartate aminotransferase, ALT: alanine transaminase, ALP: alkaline phosphatase, LDH: lactate Dehydrogenase, GGT: gamma-glutamyl transferase, CPK: creatine phosphokinase. The letters $(\mathrm{a}, \mathrm{b}$ and $\mathrm{c})$ show the statistically significant differences between the follow-up days.

* + Units are based on Klaassen, 1999 and Moritz et al., $2004 \uparrow$ Inclusion and exclusion criterias $(>0.8$ probably not FIP, $<0.6$ probably FIP) are based on Hartmann et al., 2003. 

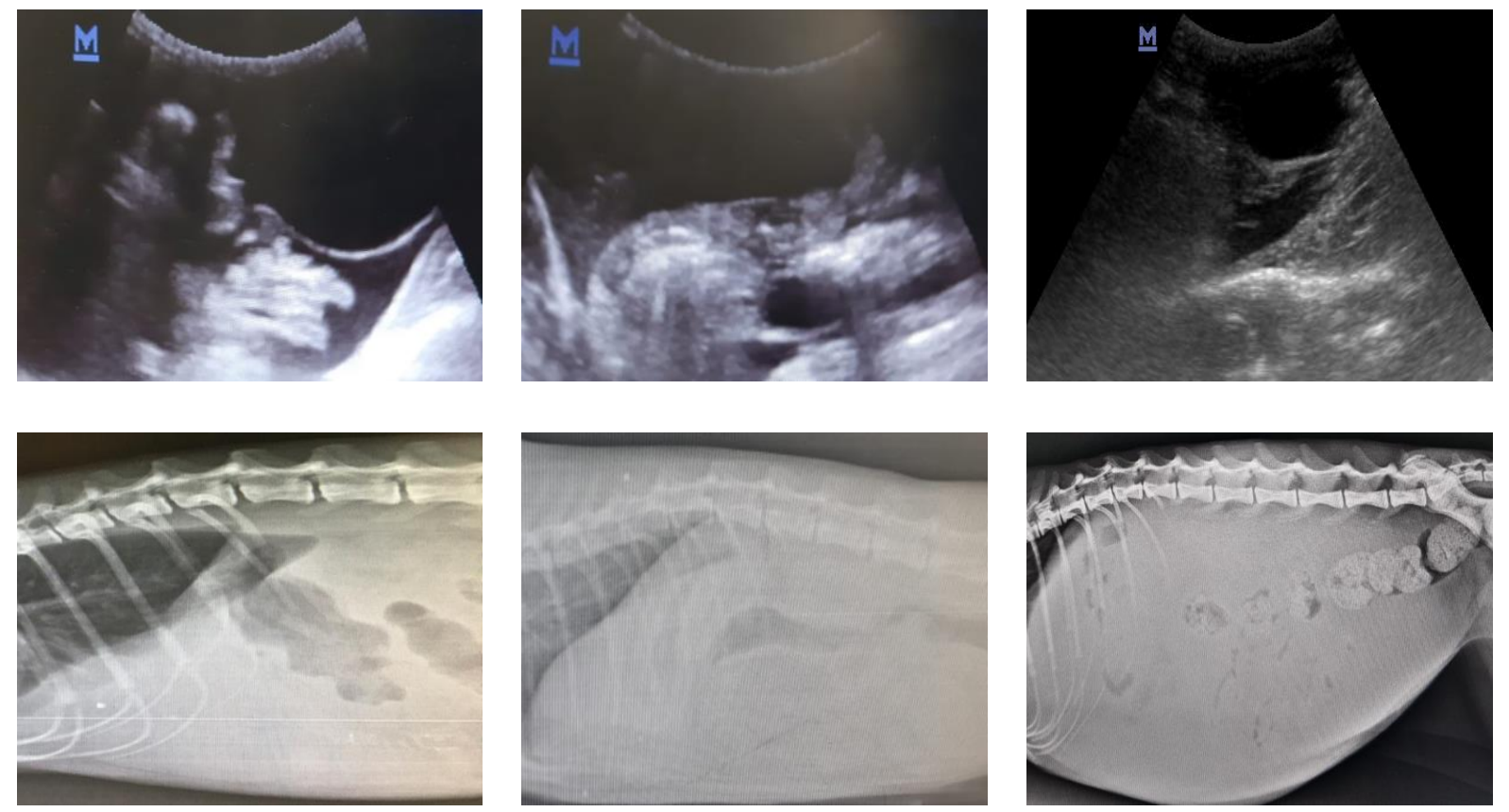

Cat 1

\section{Cat 2}

Cat 3

Figure 1. Abdominal ultrasonography (top row) and radiography (bottom row) findings of all the cats and the presence of effusion

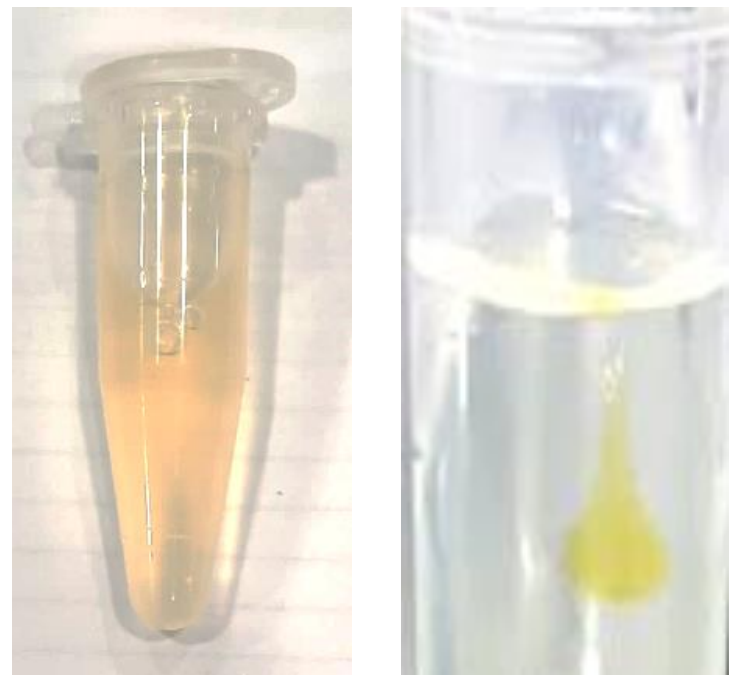

Figure 2. Physical appearance of the fluid sample taken by abdominocentesis and positive Rivolta test 


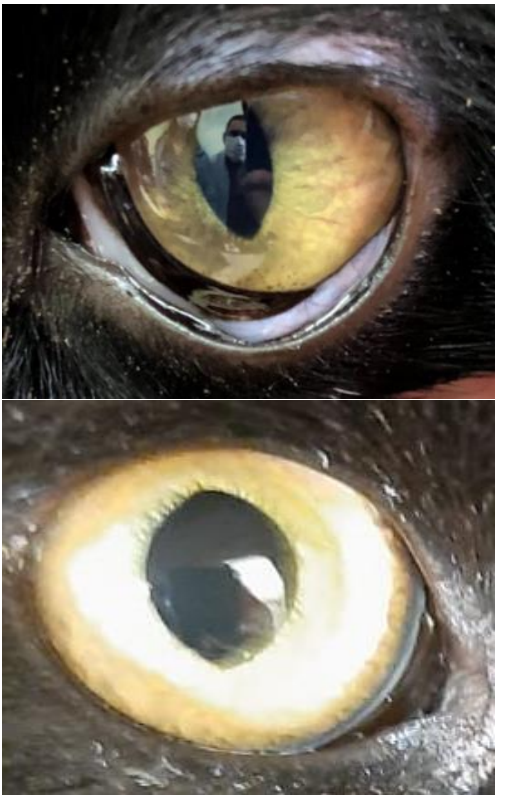

Cat 1

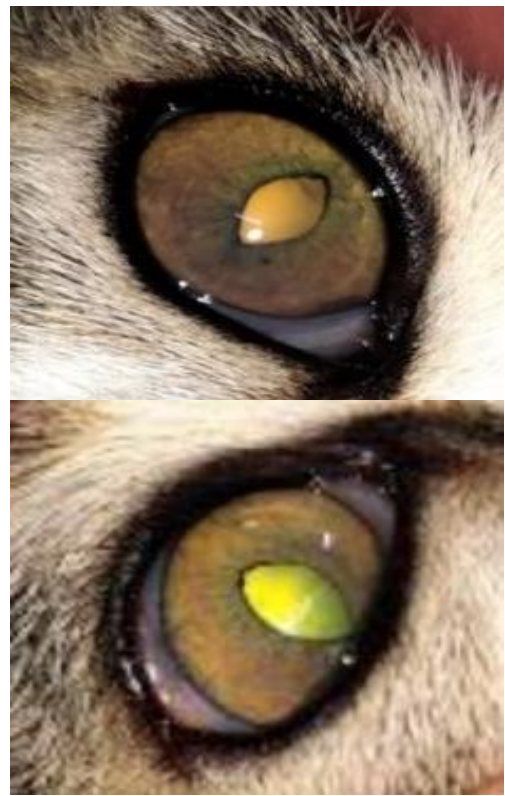

Cat 3

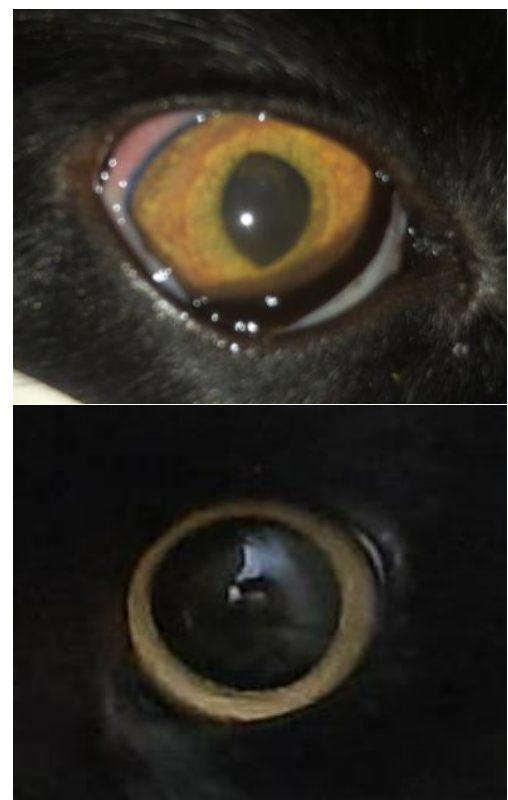

Cat 3

Figure 3. Presence of keratic precipitates and edema in all of the cats at first admission (top row) and clinical improvement after the treatment (bottom row)

\section{DISCUSSION}

Feline infectious peritonitis is an important cause of mortality in cats, and many experimental treatment studies have failed (Kim et al., 2016; Pedersen $e t$ al., 2019). In FIP infection, fatal immune-mediated vasculitis develops regardless of the clinical form (Andrew, 2000). Common clinical signs reported in the effusive form are anorexia, weight loss, lethargy, and fever (39-39.5 ${ }^{\circ} \mathrm{C}$ ) (Andrew, 2000). Ocular changes such as aqueous flare, ocular pain, corneal edema, keratic precipitate, fibrin, hyphema, perivascular cuffing, optic neuritis, retinal detachment and uveitis; neurological changes such as posture disorders and mental changes were also reported (Riemer et al., 2016). Although ocular lesions are more common in noneffusive form, they have also been reported in effusive FIP cases (Sparkes et al., 1994). In this study, the presence of ocular lesions such as pigmented keratic precipitate and corneal edema (Cat 1), pigmented keratic precipitate, aqueous flare and corneal edema (Cat 2), severe aqueous flare and corneal edema (Cat 3) were detected by ocular fundus examination. It was determined that eye lesions of all cats improved from the $5^{\text {th }}$ day of GS-441524 treatment. However, it could be interpreted that the death of all three cats around 60 days may be associated with vasculitis and related organ damage (Addie and Jarrett, 1998), and there is a need for a treatment strategy for these complications with antiviral therapy.

Recently, interest in non-invasive tests to support or exclude antemortem diagnosis of FIP has increased. Of these, is serum $\mathrm{A}: \mathrm{G}$ ratio. As cut off values, $\mathrm{A}: \mathrm{G}<0.6$ or $<0.8$ (0.80 sensitivity, 0.82 specificity) (Hartmann et al., 2003) were reported and $A: G<0.6$ ratio was reported to have high diagnostic value in inflammatory processes such as FIP (Hirschberger et al., 1995). Also, in a study conducted in a population with a high prevalence of 
FIP, it was determined that $\mathrm{A}: \mathrm{G}<0.8$ ratio has a $92 \%$ positive predictive value (Hartmann et al., 2003). The fluctuant A:G course which was determined in the present study was interpreted as a result of the inflammatory process caused by FIP and the effect of the GS-441524 administration.

In the diagnosis and prognosis of FIP, evaluating A:G ratio along with hematological and biochemical analyzes are reported to be beneficial (Felten and Hartmann, 2019). In effusive FIP cases, hematological abnormalities such as monocytosis with regenerative or nonregenerative anemia or microcytosis are reported (Sparkes et al., 1994; Paltrinieri et al., 2002). In addition, lymphopenia and band neutrophilia have been reported in $50 \%$ of cats diagnosed with effusive form of FIP (Felten and Hartmann, 2019). In the present study, in terms of hematological analysis, low MCH levels in the $5^{\text {th }}$ day and low MCHC levels in the $5^{\text {th }}, 15^{\text {th }}$ and $30^{\text {th }}$ days were determined (Table 1). The observed changes as a result of hematological analysis were interpreted as being related to the hydration status of the cats (Kipar and Meli, 2014). Moreover, these hematological abnormalities were related to the chronic course of FIP and as a result of disruption of the hematopoietic system (Weiss and Goodnough, 2005; Pedersen, 2009; Kipar and Meli, 2014; Pedersen et al., 2018).

Biochemical analysis, along with routine hematological measurements, should be performed in every cat suspected of FIP (Felten and Hartmann, 2019). Also, in treatment protocols, it is recommended to follow biochemical parameters including serum total protein, globulin, albumin, BUN, creatinine and liver enzymes such as ALT, ALP and GGT along with hemogram parameters (Paltrinieri et al., 2002; Pedersen et al., 2018). Hyperproteinemia, hypoalbuminemia and hyperglobulinemia with/without total serum protein increase and azotemia, high liver enzyme levels due to the organs affected by vasculitis are more common in cats with effusion and these have been reported in $89 \%$ of cases (Steinberg et al., 2008; Riemer et al., 2016; Felten and Hartmann, 2019). In the present study, initially high amylase and magnesium levels were determined. Similarly, increased liver enzymes and triglyceride levels indicate liver and high CPK levels indicate muscle interaction (Pedersen, 2009; Kipar and Meli, 2014; Takano et al., 2019). These findings were related to the vasculitis and involved inadequate organ and tissue perfusion which may result in failure (Hartmann, 2005; Pedersen, 2009; Kipar and Meli, 2014). The parameters that were initially high decreased on the $15^{\text {th }}$ and $30^{\text {th }}$ days (Table 1 and 2) These changes were interpreted as a positive outcome of the treatment protocol implemented in the present study (Dickinson et al., 2020). Magnesium is the most abundant cationic mineral in the body which has many roles in immune system mechanisms and it has been reported that magnesium deficiency plays a role in the development of some severe and chronic viral infections. The high magnesium level determined at the beginning of our study was interpreted as the overstimulation of the immune system (Addie and Jarrett, 1998; Dominguez et al., 2021).

The mechanism of action of 1'-cyano substituted adenine C-nucleoside ribose analogues such as GS-441524, which targets RNA viral replication, is based on the inhibition of viral RNA synthesis (Murphy et al., 2018). The parent 
molecule that turns into GS-441524 in the body is Remdesivir, which is a competitive viral RNA-dependent RNA polymerase inhibitor (Frediansyah et al., 2021). Remdesivir, which is applied as a pro-drug, turns into its active form GS441524 in the body, passes to the intercellular area and shows its antiviral effect. Remdesivir in active form is used by cell viral RNA bound to RNA polymerase instead of adenosine during viral genetic material replication. The combination of viral genetic material does not inhibit the replication process and cannot repair the viral genetic material (Ram et al., 2020). Remdesivir has hepatic (increased aminotransferase enzyme concentrations), gastrointestinal (anorexia, nausea, vomiting), respiratory (acute respiratory distress) and renal (renal tubular damage, urinary cast formation) adverse effects (Wang et al., 2020). It has been reported in naturally infected and non-neurological FIP cases in which there are recurrences or prolonged treatment period ( $>12$ weeks) in cats that received $2-4 \mathrm{mg} / \mathrm{kg} \mathrm{SC}$ of GS-441524 and GS-441524 once a day. In a study, it was reported that administration of $4 \mathrm{mg} / \mathrm{kg}$ SC once a day could be beneficial and essential for further studies (Pedersen et al., 2019; Dickinson, 2020). In this study, it was determined that GS-441524 treatment provided significant improvement in clinical and laboratory parameters of the 3 cats. The death of the cats over a period of about 60 days indicates that this therapy should be improved in order to prevent early deaths.

It has been reported that early deaths should be evaluated in the use of nucleoside analogues such as GS-441524 or its parent GC376 (Pedersen et al., 2019). In this context, it is emphasized that determining the virus load at the time of death is important and the early deaths may be related to the excessive progression of the disease, although the drug is effective (Dickinson, 2020). Pedersen et al. (2019) stated that the viral RNA load of a cat which was treated with GS-441524 and died on the $26^{\text {th }}$ day did not decreased and the clinical findings were worsened, and interpreted the cause of death of the cat as failure of the inhibition of the virus replication. GS-5734, which is the pro-drug of GS441524, has also been reported to develop resistance to Remdesivir, which is associated with amino acid mutations in RNA polymerase and proofreading exonuclease in coronaviruses reproduced by tissue culture (Agostini et al., 2018). It is indicated that in early deaths, viral RNA load, disease progression and resistance development should be considered. Inadequate or no response to treatment in cats treated with nucleoside analogues has been shown as an issue to be considered in future studies (Pedersen et al., 2019). The change in blood parameters determined in our study and early deaths before the completion of the recommended treatment period $(>12$ weeks) may be related to the persistence of virus replication and the progression of the disease or the development of resistance to GS-441524 (Agostini et al., 2018; Dickinson, 2020). Nevertheless, the effect of hepatic, gastrointestinal and renal adverse effects of Remdesivir (Wang et al., 2020) on the hematological and biochemical parameters of the present study which were determined to have fluctuant courses (Tables 1 and 2) should be considered. Also, failure to perform antemortem laboratory analyzes and postmortem necropsy / histopathological examinations in these cases and the fact that viral RNA load 
were not measured significantly limited the search for causes of death in cats.

\section{CONCLUSION}

In this study, the effects of GS-441524 administration and fluid therapy on clinical, hematological and biochemical parameters in 3 cats which were diagnosed with effusive FIP on the basis of clinical, laboratory and rapid Ag test kit result were evaluated during the follow-ups of $0^{\text {th }}, 5^{\text {th }}, 15^{\text {th }}$ and $30^{\text {th }}$ days. It was determined that the treatment protocol provided significant improvement in clinical findings on the $5^{\text {th }}$ day and in the laboratory findings on the $30^{\text {th }}$ day in 3 cats. It was learned that the cats whose were recommended to continue the treatment and monthly follow-up, died on the $58^{\text {th }}, 60^{\text {th }}$ and $62^{\text {nd }}$ days and the causes of deaths could not be investigated due to lack of necroscopic examination. As a result, the use of GS-441524 has been found to be beneficial for improving clinical, laboratory findings and animal welfare in a short time. It was concluded that clinical studies involving more cases are needed to investigate the early deaths observed during the treatment process and to determine the clinical efficacy of GS-441524 in FIP treatment.

\section{REFERENCES}

Addie, DD. and Jarrett, O. (1998): Feline coronavirus infection. p. 5869. Infectious Diseases of the Dog and Cat. 2nd ED, Philadelphia, WB Saunders.

Agostini, ML.; Andres, EL.; Sims, AC.; Graham, RL.; Sheahan, TP.; Lu, X.; Smith, EC.; Case, JB.; Feng, JY.; Jordan, R.; Ray, AS.; Cihlar, T.; Siegel, D.; Mackman, RL.;
Clarke, MO.; Baric, RS. and Denison, MR. (2018): Coronavirus susceptibility to the antiviral remdesivir (GS-5734) is mediated by the viral polymerase and the proofreading exoribonuclease. mBio, 9(2): e00221-18.

Andrew, SE. (2000): Feline infectious peritonitis. Vet. Clin. N. Am. Small. Anim. Pract., 30(5): 9871000.

Barlough, JE. (1984): Serodiagnostic Aids and Management Practice for Feline Retrovirus and Coronavirus Infections. Vet. Clin. N. Am. Small. Anim. Pract., 14(5): 955-69.

De Clercq, E. and Li, G. (2016): Approved antiviral drugs over the past 50 years. Clin. Microbiol. Rev. 29: 695-747.

Dickinson, PJ. (2020): Coronavirus Infection of the Central Nervous System: Animal Models in the Time of COVID-19. Front. Vet. Sci., 7: 584673.

Dickinson, PJ.; Bannasch, M.; Thomasy, SM.; Murthy, VD.; Vernau, KM.; Liepnieks, M.; Montgomery, E.; Knickelbein, KE.; Murphy, B. and Pedersen, NC. (2020): Antiviral treatment using the adenosine nucleoside analogue GS-441524 in cats with clinically diagnosed neurological feline infectious peritonitis. J. Vet. Intern. Med., 34(4): 1587-93.

Dominguez, LJ.; Veronese, $\quad N$. ; Guerrero-Romero, F. and Barbagallo, M. (2021): Magnesium in Infectious Diseases in Older People. Nutrients, 13: 180.

Enjuanes, L.; Almazán, F. ; Sola, I. ; Zúñiga, S.; Alvarez, E.; Reguera, J. and Capiscol, C. (2006): Biochemical aspects of coronavirus replication. Adv. Exp. Med. Biol., 581: 13-24. 
Felten, S. and Hartmann, K. (2019): Diagnosis of feline infectious peritonitis: A review of the current literature. Viruses, 11(11): 1068.

Frediansyah, A.; Nainu, F.; Dhama, K.,; Mudatsir, $M$. and Harapan, $H$. (2021): Remdesivir and its antiviral activity against Covid-19: A systematic review. Clin. Epidemiol. Glob. Health, 9: 123-27.

Hartmann, K. (2005): Feline infectious peritonitis. Vet. Clin. N. Am. Small. Anim. Pract., 35: 39-79.

Hartmann, K.; Binder, C.; Hirschberger, J.; Cole, D.; Reinacher, M.; Schroo, S.; Frost, J.; Egberink, H.; Lutz, H. and Hermanns, W. (2003): Comparison of different tests to diagnose feline infectious peritonitis. J. Vet. Intern. Med., 17: 781-90.

Hirschberger, J.; Hartmann, K., Wilhelm, N.; Frost, J.; Lutz, H. and Kraft, W. (1995): Clinical symptoms and diagnosis of feline infectious peritonitis. Tierarztl. Prax., 23: 92-9.

Kim, $\quad$ Y.; $\quad$ Liu, $\quad$ H.; $\quad$ Galasiti Kankanamalage, $\quad A C$.; Weerasekara, S.; Hua, DH.; Groutas, WC.; Chang, KO. and Pedersen, NC. (2016): Reversal of the progression of fatal coronavirus infection in cats by a broadspectrum coronavirus protease inhibitor. PLoS. Pathog., 12(3): e1005531.

Kipar, A. and Meli, ML. (2014): Feline infectious peritonitis: Still an enigma? Vet. Pathol., 51: 505-26.

Klaassen, JK. (1999): Reference Values in Veterinary Medicine. Lab. Med., 30(3): 194-97.

Moritz, A.; Fickenscher, Y.; Meyer, K.; Failing, K. and Weiss DJ. (2004): Canine and feline hematology reference values for the ADVIA
120 hematology system. Vet. Clin. Pathol., 33(1): 32-8.

Murphy, BG.; Perron, M.; Murakami, E.; Bauer, K.; Park, Y.; Eckstrand, C.; Liepnieks, M. and Pedersen, NC. (2018): The nucleoside analog GS-441524 strongly inhibits feline infectious peritonitis (FIP) virus in tissue culture and experimental cat infection studies. Vet. Microbiol., 219: 226-33.

Paltrinieri, S.; Comazzi, S.; Spagnolo, V. and Giordano, A. (2002): Laboratory changes consistent with feline infectious peritonitis in cats from multicat environments. J. Vet. Med. A. Physiol. Pathol. Clin. Med., 49: 503-10.

Pedersen, NC.; Perron, M.; Bannasch, M.; Montgomery, E.; Murakami, E.; Liepnieks, $M$. and Liu, H. (2019): Efficacy and safety of the nucleoside analog GS-441524 for treatment of cats with naturally occurring feline infectious peritonitis. J. Feline. Med. Surg., 21(4): 271-81.

Pedersen, NC. (2009): A review of feline infectious peritonitis virus infection: 1963-2008. J. Feline. Med. Surg., 11: 225-58.

Pedersen, NC.; Kim, Y.; Liu, H.; Galasiti Kankanamalage, AC.; Eckstrand, C.; Groutas, WC.; Bannasch, M.; Meadows, JM. and Chang, KO. (2018): Efficacy of a 3C-like protease inhibitor in treating various forms of acquired feline infectious peritonitis. J. Feline. Med. Surg., 20(4): 378-92.

Ram, AH.; Badgujar, KC.; Zanznay, R.; Kadam, H. and Badgujar, VC. (2020): Remdesivir for COVID-19: A review of pharmacology, mechanism of action, in-vitro activity and clinical use based on 
available case studies. J. Drug. Deliv. Ther., 10: 264-70.

Riemer, F.; Kuehner, KA.; Ritz, S.; Sauter-Louis, C. and Hartmann, $K$. (2016): Clinical and laboratory features of cats with feline infectious peritonitis--a retrospective study of 231 confirmed cases (2000-2010). J Feline Med Surg., 18(4): 348-56.

Sparkes, AH.; Gruffydd-Jones, TJ. and Harbour, DA. (1994): An appraisal of the value of laboratory tests in the diagnosis of feline infectious peritonitis. J. Am. Anim. Hosp. Assoc., 30: 345.

Steinberg, TA.; Boettcher, IC.; Matiasek, K.; Hirschvogel, K.; Hartmann, K.; Kunz, A. and Fischer, A. (2008): Use of albumin quotient and igg index to differentiate blood- vs brain-derived proteins in the cerebrospinal fluid of cats with feline infectious peritonitis. Vet. Clin. Pathol., 37: 207-16.

Takano, T.; Akiyama, M.; Doki, T. and Hohdatsu, T. (2019): Antiviral activity of itraconazole against type
I feline coronavirus infection. Vet. Res., 50: 5.

Wang, Y.; Zhang, D.; Du, G.; Du, R.; Zhao, J.; Jin, Y.; Fu, S.; Gao, L.; Cheng, Z.; Lu, Q.; Hu, Y.; Luo, G.; Wang, K.; Lu, Y.; Li, H.; Wang, S.; Ruan, S.; Yang, C.; Mei, C.; Wang, Y.; Ding, D.; Wu F.; Tang, X.; Ye, X.; Ye, Y.; Liu, B.; Yang, J.; Yin, W.; Wang, A.; Fan, G.; Zhou, F.; Liu, Z.; Gu, X.; Xu, J.; Shang, L.; Zhang, Y.; Cao, L.; Guo, T.; Wan, Y.; Qin, H.; Jiang, Y.; Jaki, T.; Hayden, FG.; Horby, PW.; Cao, B. and Wang, C. (2020): Remdesivir in adults with severe Covid-19: a randomised, double-blind, placebocontrolled, multicentre trial. Lancet, 395(10236): 1569-78.

Weiss, G. and Goodnough, L.T. (2005): Anemia of chronic disease. N. Engl. J. Med., 352: 1011-23.

Worthing, KA.; Wigney, DI.; Dhand, NK.; Fawcett, A.; McDonagh, P.; Malik, R. and Norris, JM. (2012): Risk factors for feline infectious peritonitis in Australian cats. J. Feline. Med. Surg., 14(6): 405-12. 